\title{
The First Case of Successful Stenting of the Dissection of the Ascending Aorta and the Aortic Arch that Occurred During Surgical Correction of the Supralvular Aortic Stenosis in a Child with the Williams Syndrome
}

\author{
Manolis Georgievich Pursanov, MD, Professor*,Konstantin Valentinovich Shatalov, Professor, \\ Andrey Vasiljevitch Sobolev, PhD, Irina Vladimirovna Arnautova, PhD \\ Department of Endovascular and Intraoperative Diagnostic and Treatment of Cardiovascular Disease, Bakoulev Scientific Center for \\ Cardiovascular Surgery, Moscow, Russian Federation
}

\begin{abstract}
Congenital supravalvular aortic stenosis (SVAS), in vast majority of cases is a manifestation of Williams syndrome. Surgical correction of this pathology is a "gold standard" for treatment in these patients. One of the most dangerouse potential complications in surgical repair of this disease is acute dissection of the ascending aorta, arising in $0.7 \%$ of cases. This complication can be attributed to both surgical errors and or due to the anatomical features of the aortic wall. We report on a pediatric patient with Williams syndrome, $2.3 \mathrm{yr}, \mathbf{1 1 . 9}$ kg, who underwent surgical repair for supravalvar aortic stenosis using the Doty technique. Aortic dissection was diagnosed using aortography. This was managed by implanting two Valeo stents.
\end{abstract}

Copyright $\odot 2018$ Science International Corp.

\section{Key Words}

Williams syndrome • Aortic dissection • Stenting

\section{Introduction}

Congenital supravalvular aortic stenosis (SVAS), in the vast majority of cases, is a manifestation of Williams syndrome or other pathological condition associated with mutation of the 7q11.23 gene [1-4]. In

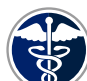

Fax +1 2037853346

E-Mail: jshd@scienceinternational.org

http://structuralheartdisease.org/ (c) 2018 Journal of Structural Heart Disease Published by Science International Corp. ISSN 2326-4004

Accessible online at: http://structuralheartdisease.org/ patients with Williams syndrome or SVAS, other obstructive vascular lesions are often present such as coarctation of the aorta and peripheral stenoses of the pulmonary arteries. Patients with Williams syndrome also often have a bicuspid aortic valve and mitral valve prolapse, as well as various heart rhythm disturbances [6-8].

SVAS is a complex pathology that may present in a wide variety of clinical and morphological forms. The most common form is aortic lumen obstruction localized directly above the aortic valve [5,9]. The severity of stenosis is the main factor determining the severity of hemodynamic burden and thus the clinical manifestation of this pathology. In most cases, the clinical picture of the disease manifests during childhood or adolescence, and most patients require surgical correction of the defect, which is performed under cardiopulmonary bypass $[1,10,11]$.

Although surgery is safe and successful in most cases, there is the rare potential complication of dissection of the ascending aorta after its surgical reconstruction. This complication can be attributed to both surgical errors and anatomical features of the aortic wall. The incidence of this complication is $0.6 \%$ [1213]. Here, we describe a child with Williams syndrome

* Corresponding Author:

Manolis Georgievich Pursanov, MD

Department of Endovascular and Intraoperative Diagnostic and Treatment of Cardiovascular Disease

Bakoulev Scientific Center for Cardiovascular Surgery

Rublevskoe Shosse 135, Россия, Moscow, 121552, Russian Federation

Tel. +8 49541478 89; Fax: +8 92652932 23; E-Mail: mpursanov@gmail.com 


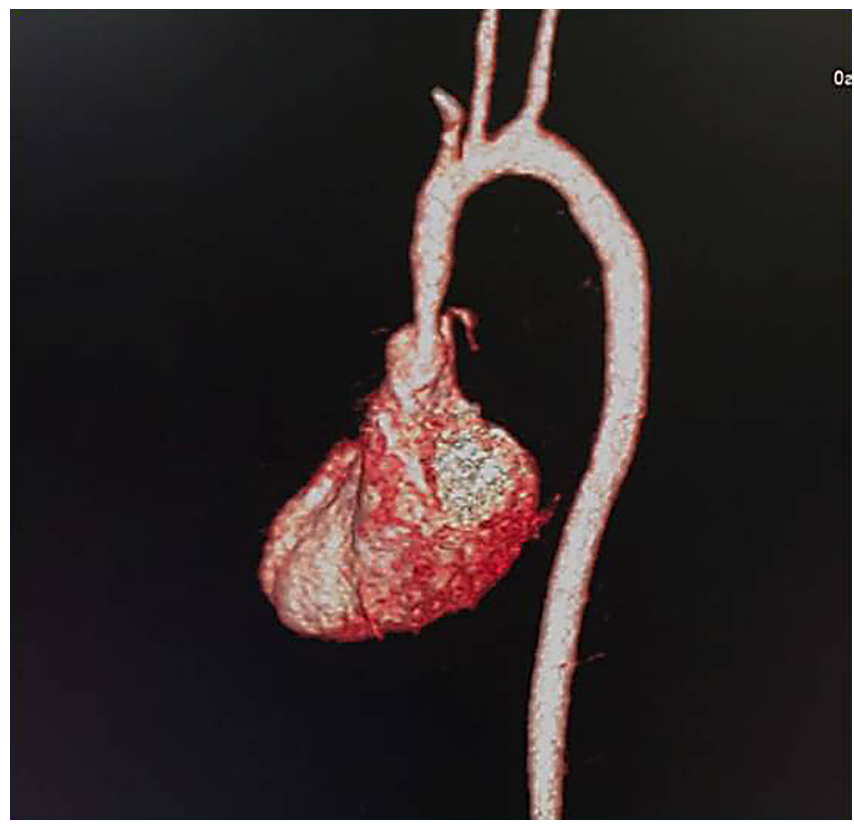

Figure 1. Multi-slice computed tomography of the heart with contrasting. 3D-reconstruction (VRT). A pronounced narrowing of the sinotubular zone of the ascending aorta in a patient with Williams syndrome is visualized.

and SVAS who underwent successful hybrid stenting of an extensive dissection of the ascending aorta extending to the aortic arch.

\section{Case Presentation}

Patient K. was 2.25 years and weighed $11.9 \mathrm{~kg}$. He was diagnosed with Williams syndrome with severe SVAS. Echocardiography revealed the presence of concentric hypertrophy of the left ventricle with normal ejection fraction of $68 \%$. The peak gradient across the ascending aorta was $100 \mathrm{mmHg}$. He also had moderate stenosis of the branch pulmonary arteries, with a peak gradient across the entire right ventricle outflow tract of $11 \mathrm{mmHg}$. He also had a patent foramen ovale. His echocardiogram showed left axis deviation and left ventricle hypertrophy. Chest X-ray demonstrated cardiomegaly, mainly due to left heart hypertrophy, with a cardiothoracic ratio of $67 \%$.

Multislice computed tomography was performed to clarify the anatomy and determine the localization of the lesion and severity of the stenosis (Figure 1). We observed severe aortic stenosis at the level of the sino-tubular junction measuring $4.5 \mathrm{~mm}$. The isth- mus and aortic arch diameters were $6 \mathrm{~mm}$. Brachiocephalic vessels originated from separate origins, with brachocephalic trunk, left common carotid artery, and left subclavial artery diameters of $3.0,2.8$, and 3.8 $\mathrm{mm}$, respectively.

Due to his clinical symptoms of fatigue associated with severe stenosis and left ventricle hypertrophy, we decided to perform surgical repair of the ascending aorta using the Doty technique. Median sternotomy was performed, and under cardiopulmonary bypass with moderate hypothermia $\left(28^{\circ} \mathrm{C}\right)$, the ascending aorta was opened via a longitudinal incision toward the non-coronary sinuses of Valsalva almost to the aortic valve annulus. The second incision crossed the stenotic sinotubular zone, forming a reverse " $Y$ " shape in the direction of the right coronary sinus anterior to the intracoronary commissure. Visually, we noticed a thickening of the aortic wall to a diameter of $3.5 \mathrm{~mm}$. A reverse " $Y$ "-shaped xenopericardial patch was made and fixed to the edges of the aortic incision using a premilene suture starting from the right coronary sinus. The suture site was reinforced with medical hemostatic glue [14].

The patient was weaned off bypass without much difficulty. However, there was a significant hemodynamic difference in systolic pressure between the ascending aorta and the radial arteries to the right and left of $110 \mathrm{~mm} \mathrm{Hg}$. Dissection of the aorta was suspected. To confirm this, using a mobile angiocardiographic unit (OEC 9900, GE Healthcare, Chicago, IL, USA), we performed ascending aortography using the right femoral arterial access. The systolic pressure gradient between the ascending and descending aorta was $177 \mathrm{~mm} \mathrm{Hg}$. Aortography revealed the presence of aortic dissection, with an intimal flap distal to the aortic patch on the ascending aorta with extension to the aortic arch and brachiocephalic vessels (Figure 2).

Given a high risk of surgical correction under cardiopulmonary bypass, a hybrid approach was proposed. We decided to perform stenting of the dissected part of the aorta. A 6-F Mullins sheath (Cook Medical, Bloomington, IN, USA) was placed in the ascending aorta. A standard diagnostic guidewire was exchanged for a 0.035" Amplatz super-stiff guide wire with a 1-cm soft tip (Boston Scientific, Marlborough, MA, USA) to deliver the stent into the ascending aorta so that it would completely cover the zone of dis- 


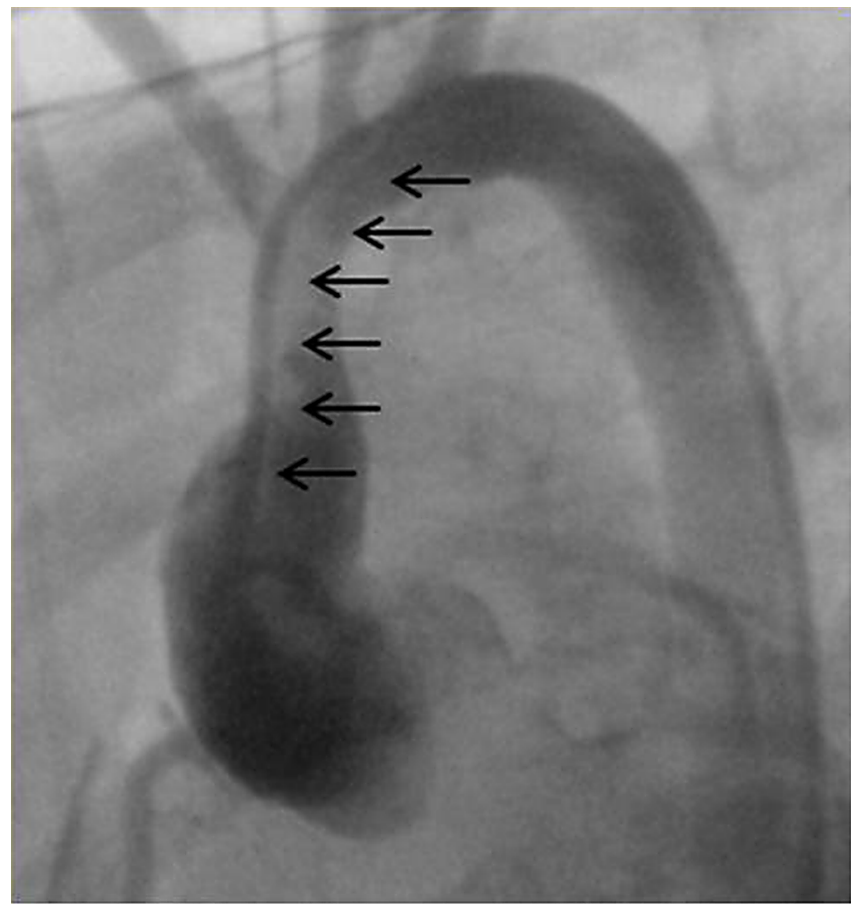

Figure 2. Aortography in the left oblique projection. There is a dissection of the ascending section and the aortic arch (indicated with arrows). The dissection extends to the mouth of the brachiocephalic trunk and the left common carotid artery.

section to the point of origin of the brachiocephalic vessels. A 18-mm Valeo stent (Bard, Murray Hill, NJ, USA) was attached to a 8-mm balloon deployed to $10 \mathrm{~atm}$. After stent implantation, however, there was no significant change in systolic pressure gradient. Therefore, a second 26- $\mathrm{mm}$ Valeo stent on a 8- $\mathrm{mm}$ balloon was implanted covering the whole surface of the aortic arch. Repeat aortography revealed proper implantation of both stents covering the entire zone of dissection. Patency of the brachiocephalic arteries was preserved (Figure 3). Invasive pressure measurement after stent implantation showed minimal residual systolic pressure of $15 \mathrm{~mm} \mathrm{Hg}$. The child left the operating room on adrenaline at a dose of $0.1 \mu \mathrm{g} / \mathrm{kg} /$ $\min$.

The child was extubated after 20 hours. Anticoagulant therapy was initiated using heparin at a rate of $200 \mathrm{U} / \mathrm{kg} /$ day for 3 days followed by aspirin at a dose of $50 \mathrm{mg} /$ day. The patient was discharged home on postoperative day 13 . Unfortunately, the parents refused postoperative follow-up consultation in our

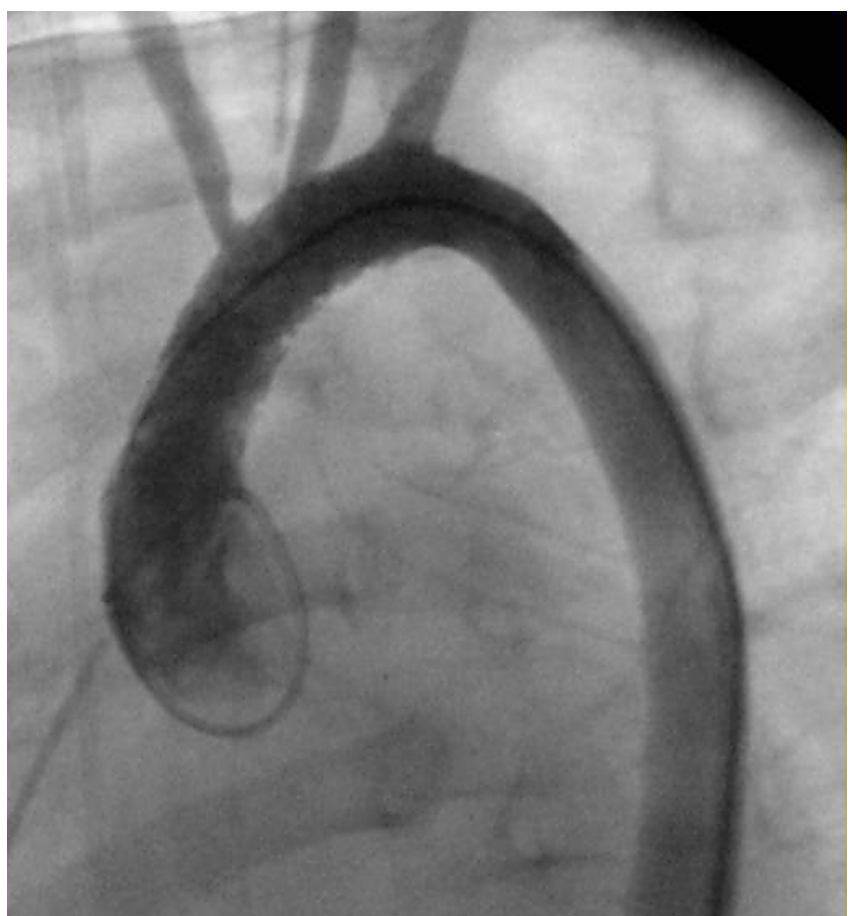

Figure 3. Aortography in the left oblique projection. After the implantation of the two Valeo stents into the ascending aorta and the aortic arch, there are no signs of aortic narrowing and dissection, the brachiocephalic vessels are completely passable.

center due to a stated good clinical status of their child and distant place of residence.

\section{Discussion}

Surgical correction of SVAS in patients with Williams syndrome is safe and effective. However, a rare acute complication of dissection of the ascending aorta can lead to an unfavorable prognosis. There are no clear recommendations or algorithms for action in cases of dissection. In adult patients with acute dissection, prosthetic material can be used to repair the dissection. In children, however, this is more difficult and sometimes not feasible. Therefore, in such cases, using endovascular techniques to eliminate acute aortic dissection is potentially a promising solution. We did not find descriptions of similar clinical cases in young children in the literature. Available reports discussed planned endovascular and hybrid interventions to eliminate residual stenosis of the ascending aorta and aortic arch after previously performed reconstructive surgical interventions [15-16]. 
Despite good immediate results in our case, a future increase in systolic pressure gradient is possible due to growth of the child and neointimal proliferation $[15,16]$. This complication often occurs after stenting of vessels, especially in children with Williams syndrome or other genetic defects accompanied by connective tissue dysplasia, which are characterized by a tendency to increased proliferation of the endothelium [17]. However, in our case of hybrid management of an urgent obstruction of the ascending aorta and aortic arch, we used Valeo stents, which have the capacity for further expansion to an adult size if and when needed [18]. Therefore, our case demonstrates the possibility of intraoperative diagnosis and elimination of a formidable complication such as acute aortic dissection using endovascular technologies in pediatric cardiac surgery.

\section{Conflict of Interest}

The authors have no conflict of interest relevant to this publication.

\section{Comment on this Article or Ask a Question}

\section{References}

1. Kramer P, Absi $D$, Hetzer R, Photiadis J, Berger F, Alexi-Meskishvili V. Outcome of surgical correction of congenital supravalvular aortic stenosis with two- and three-sinus reconstruction techniques. Ann Thorac Surg. 2014;97:634-640. DOI: 10.1016/j.athoracsur.2013.09.083

2. Merla G, Brunetti-Pierri N, Piccolo P, Micale L, Loviglio MN. Supravalvular aortic stenosis: Elastin arteriopathy. Circ Cardiovasc Genet. 2012;5:692-696. DOI: 10.1161/CIRCGENETICS.112.962860

3. Adams GN, Schmaier AH. The Williams-Beuren Syndrome-a window into genetic variants leading to the development of cardiovascular disease. PLoS Genet. 2012;8:8-10. DOI: 10.1371/journal. pgen.1002479

4. Samanich JM, Levin TL, Berdon WE. The clinical and genetic distinction between familial supravalvular aortic stenosis (Eisenberg syndrome) and Williams-Beuren syndrome. Pediatr Radiol. 2012;42:1269. DOI: 10.1007/s00247-012-2475-2

5. Macdonald ST, Walker F. Subvalvular and supravalvular aortic stenosis. In: Gatzoulis M., Webb G., Daubeney P, editors. Diagnosis and management of adult congenital heart disease. Amsterdam: Elsevier; 2011. p. 236-242. DOI: 10.1016/B978-0-70203426-8.00032-0

6. Braverman AC, Beardslee MA. The bicuspid aortic valve. In: Otto $C M$, Bonow R, editors. Valvular heart disease: A companion to Braunwald's Heart Disease. Admsterdam: Elsevier. 2009. p.173-174. DOI: 10.1016/ B978-1-4160-5892-2.00011-8

7. Ko JM. Genetic syndromes associated with congenital heart disease. Korean Circ J. 2015;45:357-361. DOI: 10.4070/ kcj.2015.45.5.357

8. Kahr PC, Gupta SK, Kothari SS, Ramakrishnan S. Classical supravalvar aortic stenosis and peripheral pulmonary stenosis. Images Paediatr Cardiol. 2014;16:1-4. PMID: 26236365

9. McCarty HM, Tang $X$, Swearingen $\mathrm{CJ}$, Collins RT 2nd. Comparison of electrocardiographic QTC duration in patients with supravalvar aortic stenosis with versus without Williams syndrome. Am J Cardiol. 2013;111:1501-1504. DOI: 10.1016/j.amjcard.2013.01.308

10. Deo SV, Burkhart HM, Dearani JA, Schaff HV. Supravalvar aortic stenosis: Current surgical approaches and outcomes. Expert Rev Cardiovasc Ther. 2013;11:879-890. DOI: 10.1586/14779072.2013.811967

11. Mitchell MB, Goldberg SP. Supravalvar aortic stenosis in infancy. Semin Thorac Cardiovasc Surg Pediatr Card Surg Annu. 2011;14:85-91. DOI: 10.1053/j. pcsu.2011.01.013

12. Collins RT 2nd, Kaplan P, Somes GW, Rome JJ. Long-tern outcomes of patients with cardiovascular abnormalities and Williams syndrome. Am J Cardiol. 2010;105:874878. DOI: 10.1016/j.amjcard.2009.10.069

13. Eugene J, Aronow WS, Stemmer EA. Acute aortic dissection during cardiopulmonary bypass. Clin Cardiol. 1981;4:356-359. DOI: 10.1002/clc.4960040610

14. Doty DB, Polansky DB, Jenson CB. Supravalvular aortic stenosis. Repair by extended aortoplasty. J Thorac Cardiovasc Surg. 1977;74:362-371. PMID: 142867
15. deLezo JS, Pan M, Segura J, Romero $M$, Pavlovic, D. Supravalvar aortic stenosis. In: Sievert H, Qureshi SA, Wilson N, Hijazi ZM, editors. Percutaneous interventions for congenital heart disease. Boca Raton: CRC Press. 2007. p.469-475. DOI: 10.3109/9780203018262-63

16. Bokeriya LA, Alekyan BG, Pursanov MG. Stentirovanie nadklapannogo stenoza aorty Rukovodstvo po rentgenehndovaskulyarnoj hirurgii serdca i sosudov pod red. Bokeriya L A Alekyan B G. 2008;285-288.

17. Haas NA, Happel CM, Blanz U, Laser KT, Kantzis M, Kececioglu D, et al. Intraoperative hybrid stenting of recurrent coarctation and arch hypoplasia with large stents in patients with univentricular hearts. Int J Cardiol. 2016;204:156-163. DOI: 10.1016/j. ijcard.2015.11.136

18. Kudumula K, Noonan P, Taliotis D, Duke C. Implantation and preliminary follow-up of the Bard Valeo stent in pulmonary artery stenosis. Catheter Cardiovasc Interv. 2014;84:197-203. DOI: 10.1002/ccd.25443

Cite this article as: Pursanov MG, Shatalov KV, Sobolev AV, Arnautova IV. The First Case of Successful Stenting of the Dissection of the Ascending Aorta and the Aortic Arch that Occurred During Surgical Correction of the Supralvular Aortic Stenosis in a Child with the Williams Syndrome. Structural Heart Disease. 2018;4(1):17-20. DOI: https://doi. org/10.12945/j.jshd.2018.031.17 